\title{
ERRATUM
}

Osamu Kabutomori • Yuzuru Kanakura •

Yoshinori Iwatani

\section{Inflammation markers and liver dysfunction}

Published online: 5 March 2005

(C) Springer-Verlag 2005

\section{Ann Hematol (2005) 84:136}

In the original online publication of this article, Fig. 1 was unfortunately omitted. We apologise for this mistake. The correct version of Fig. 1 with all parts included, can be seen here.

The online version of the original article can be found at http://dx. doi.org/10.1007/s00277-004-0967-3

O. Kabutomori $(\bowtie) \cdot$ Y. Kanakura

Central Laboratory for Clinical Investigation,

Osaka University Hospital,

2-15 Yamada-Oka, Suita,

Osaka, 565-0871, Japan

e-mail: kabto@highway.ne.jp

Tel.: +81-6-68796658

Fax: +81-6-68796660

Y. Iwatani

Division of Biomedical Informatics,

Course of Health Science,

Graduate School of Medicine,

Osaka University,

Osaka, Japan (a)

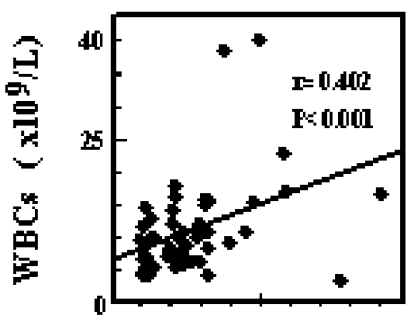

(b)
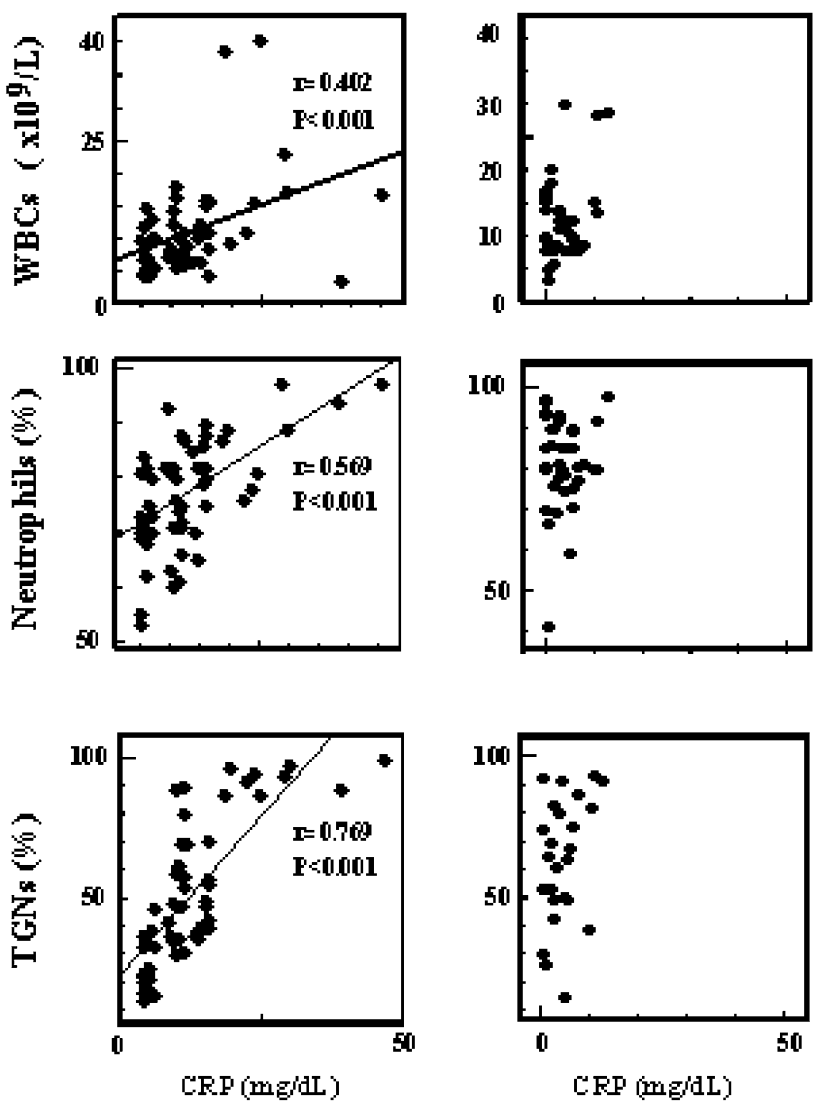

Without hrer dysfunc tion

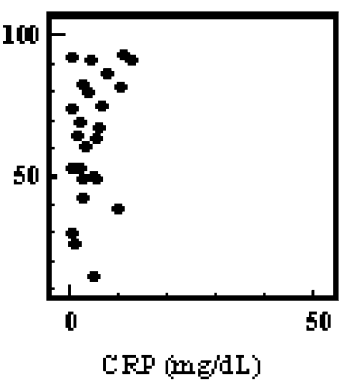

With hiver dysfunc tion

Fig. 1 Correlation between C-reactive protein $(C R P)$, white blood cells $(W B C s)$, neutrophils (\%), and toxic granulation neutrophils $(T G N s)(\%)$ in patients with inflammatory disease a without liver dysfunction and $\mathbf{b}$ with liver dysfunction. 